\title{
Spectral absorption properties of atmospheric aerosols
}

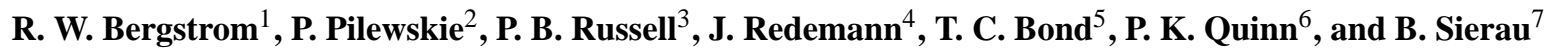 \\ ${ }^{1}$ Bay Area Environmental Research Institute, Sonoma, CA, USA \\ ${ }^{2}$ Laboratory for Atmospheric and Space Physics, Department of Atmospheric and Oceanic Sciences, University of Colorado, \\ Boulder, CO, USA \\ ${ }^{3}$ NASA Ames Research Center. Moffett Field, CA, USA \\ ${ }^{4}$ Bay Area Environmental Research Institute, Ventura, CA, USA \\ ${ }^{5}$ University of Illinois, Champaign-Urbana, IL, USA \\ ${ }^{6}$ Pacific Marine Environmental Laboratory, National Oceanic and Atmospheric Administration, Seattle, Washington, USA \\ ${ }^{7}$ Institute for Atmospheric and Climate Science, ETH Zurich, Zurich, Switzerland
}

Received: 19 June 2007 - Published in Atmos. Chem. Phys. Discuss.: 24 July 2007

Revised: 16 October 2007 - Accepted: 30 October 2007 - Published: 4 December 2007

\begin{abstract}
We have determined the solar spectral absorption optical depth of atmospheric aerosols for specific case studies during several field programs (three cases have been reported previously; two are new results). We combined airborne measurements of the solar net radiant flux density and the aerosol optical depth with a detailed radiative transfer model for all but one of the cases. The field programs (SAFARI 2000, ACE Asia, PRIDE, TARFOX, INTEX-A) contained aerosols representing the major absorbing aerosol types: pollution, biomass burning, desert dust and mixtures. In all cases the spectral absorption optical depth decreases with wavelength and can be approximated with a power-law wavelength dependence (Absorption Angstrom Exponent or AAE). We compare our results with other recent spectral absorption measurements and attempt to briefly summarize the state of knowledge of aerosol absorption spectra in the atmosphere. We discuss the limitations in using the AAE for calculating the solar absorption. We also discuss the resulting spectral single scattering albedo for these cases.
\end{abstract}

\section{Introduction}

One of the largest uncertainties in the radiative forcing of climate is due to aerosols. A substantial fraction of that uncertainty has been associated with the scattering and absorption of solar radiation by anthropogenic aerosols in cloud-free conditions. In recent years, a number of studies and field programs have been conducted that have aided in reducing

Correspondence to: R. W. Bergstrom

(bergstrom@baeri.org) the uncertainty of the direct aerosol radiative forcing (IPCC, 2006). However there is a continuing interest in measuring the aerosol effects on solar radiation, clouds and climate, and future field programs are in the planning stage (such as the IPY project POLARCAT).

Certain atmospheric aerosols absorb solar radiation, specifically carbonaceous particles and mineral dust. This absorption affects the atmosphere by reducing the radiation reaching the surface and increasing the temperature aloft. The effects of absorbing aerosols are routinely modeled and accurate aerosol radiative properties are needed. In fact, as Bond and Sun (2005) state concerning the predicted effects of black carbon: while climate "models disagree with regard to simulated temperature changes, differing values of TOA [top of atmosphere] forcing per mass (normalized forcing) can largely be explained by assumptions in particle transport and optical properties."

Absorptive properties have been used to infer black carbon mass (Hansen et al., 1984), to identify aerosol sources (Clarke et al., 2007), to differentiate between black carbon and dust (Collaud Coen et al., 2004; Fialho et al., 2005; Meloni et al., 2006) and to identify absorbing aerosols by satellite (Torres et al., 2005). Each of these efforts relies on accurate information about aerosol absorptive properties.

This paper attempts to briefly summarize the state of knowledge on aerosol absorption spectra in the atmosphere. It presents the aerosol absorption measured in five different field campaigns and discusses the results in light of other measurements. We show that the absorption coefficient decreases monotonically with wavelength in all cases and can be approximated by a power-law expression (i.e. an Absorption Angstrom Exponent or AAE). However, the slope of the

Published by Copernicus Publications on behalf of the European Geosciences Union. 


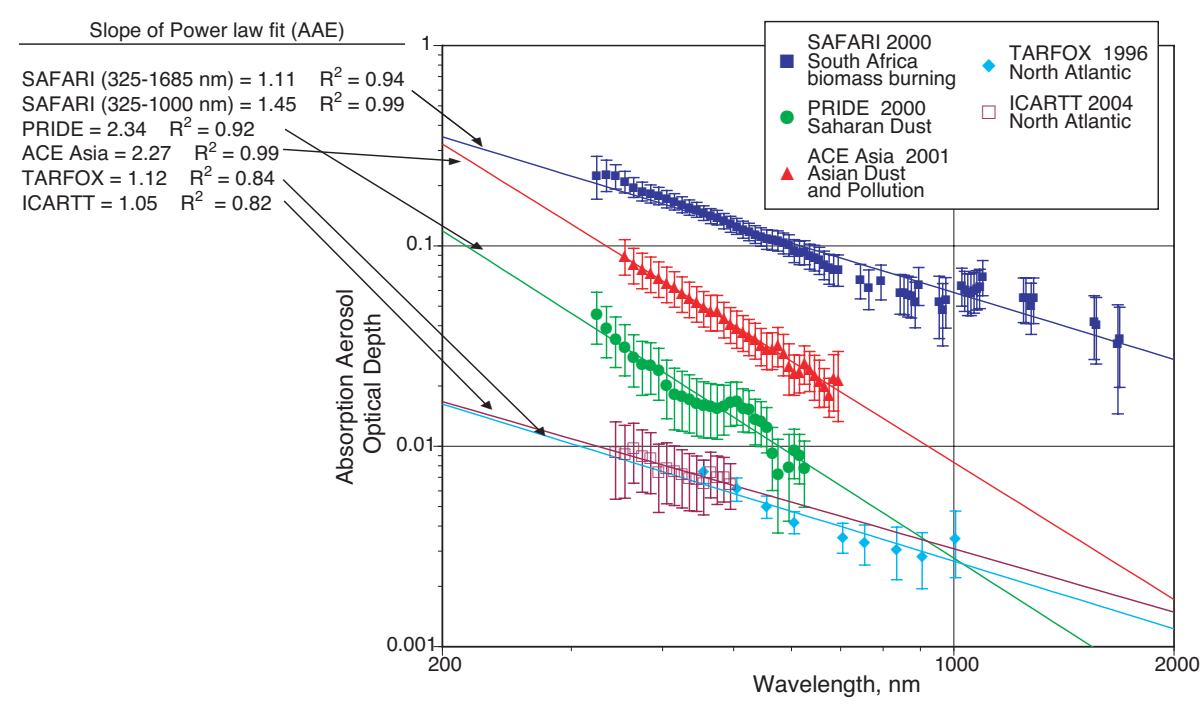

Fig. 1. The absorption aerosol optical depth versus wavelength for selected cases for five different field programs. The curve fit straight line represents the best-fit Angstrom Absorption Exponent for the wavelength region.

absorption (or the value of the AAE) depends on the aerosol material.

\section{Measurement methods}

The five different field campaigns are listed in Table 1. We used aircraft measurements of solar net radiant flux density and aerosol optical depth to determine the spectral absorption coefficient for atmospheric aerosols in the last four of the experiments. The Solar Spectral Flux Radiometer (SSFR; Pilewskie et al., 2003) was used to simultaneously measure upwelling and downwelling spectral irradiance between 350 and $1670 \mathrm{~nm}$ with resolution between $8-12 \mathrm{~nm}$. The NASA Ames Airborne Tracking Sunphotometer (AATS-14; Russell et al., 1999) measured the direct solar beam transmission at 14 wavelengths between 354 and $2139 \mathrm{~nm}$ in narrow channels yielding the aerosol optical depth.

We estimated the absorption optical depth by matching the data with predictions from a detailed solar radiative transfer model (Bergstrom et al., 2003). We matched either the measured absorption in the aerosol layer or the change in downward flux with optical depth (Redemann et al., 2006). The TARFOX field campaign did not include spectral solar flux measurements. Instead, filter samples were taken aboard an aircraft and analyzed for absorption in the UK Met Office laboratory (Bergstrom et al., 2002).

\section{Absorption optical depth}

The spectral absorption optical depths from the five field campaigns are shown in Fig. 1. The absorption optical depth follows a relatively smooth decrease with wavelength for all cases and can be approximated with a power-law wavelength dependence (Absorption Angstrom Exponent or AAE). By convention the AAE is the negative of the slope of the absorption on a log-log plot. Use of a linear fit to the slope of an optical coefficient on a log-log plot is not new by any means. The original Angstrom reference is from 1929 and the Angstrom exponent has been routinely used in describing aerosol extinction and scattering coefficients (for example, see Reid et al. (1999) for the use of the Angstrom exponent to estimate the variability of the optical properties of smoke particles in Brazil).

The utility of the Angstrom exponent for aerosol scattering is that the value of the exponent depends primarily on the size of the particles ranging from 4 for very small particles (Rayleigh scattering) to 0 for very large particles (such as cloud drops). Thus the Angstrom exponent for atmospheric aerosol scattering varies between the two limits depending on the size of the particles.

The analogous small particle limit for absorption (a Rayleigh-like absorption) can be shown to have a $\lambda^{-1}$ dependence for spherical particles if the refractive indices are constant (Bergstrom, 1973; Bohren and Hufman, 1983). Black carbon (or light absorbing carbon, LAC) appears to have a relatively constant index of refraction and the particles are mostly small fractal agglomerates and thus should have an AAE of 1 (Bergstrom et al., 2002).

In Fig. 1 for the two urban aerosol cases (TARFOX and ICARTT) the AAE is close to 1 . For the cases with dust aerosols (ACE Asia and PRIDE) the AAE is larger than 2. For the biomass burning case (SAFARI) the AAE is 1 for the entire wavelength region but 1.45 for the region of $300 \mathrm{~nm}$ to $1000 \mathrm{~nm}$. Since the TARFOX absorption optical depth was not measured - only the absorption coefficient, a normalized 
Table 1. Field programs.

\begin{tabular}{llllll}
\hline Name & Date & Location & Type of Aerosol & Measurement Method & Reference \\
\hline TARFOX & July 1999 & East Coast US & Urban Pollution & Filter transmission & Bergstrom et al., 2002 \\
SAFARI 2000 & August 2000 & Southern Africa & Biomass burning & SSFR/AATS; FD & Bergstrom et al., 2003 \\
ACE Asia & August 2001 & Sea of Japan & Dust; Urban mixed & SSFR/AATS; FD & Bergstrom et al., 2005 \\
PRIDE & March 2002 & Puerto Rico & Saharan dust & SSFR/AATS; FD & Reid et al., 2003 \\
ICARTT & July 2004 & East Coast US & Urban Pollution & SSFR/AATS; GM & Redemann et al., 2006 \\
& & & & & Sierau et al., 2006 \\
\hline
\end{tabular}

FD = Flux Divergence $;$ GM = Gradient Method

absorption coefficient was plotted at roughly the same magnitude as the ICARTT results.

Atmospheric aerosol properties in general have a great deal of variability, so Fig. 1 represents only averages or individual cases. Since these are data taken from an airplane far from the sources, the data represent aged particles. This variability is illustrated in Fig. 2 taken during the recent GoMACCS (Gulf of Mexico Atmospheric Composition and Climate Study, August-September, 2006) field campaign. The figure shows the cumulative frequency of occurrence of the aerosol AAE for three different wavelength regions for mainly offshore wind conditions during the entire cruise. The data were taken by a three-wavelength PSAP (Particle Soot Absorption Photometer, a filter-based measurement) aboard the NOAA RV Ronald H. Brown at one-second intervals but averaged over a one-minute time interval.

Figure 2 shows the range of variability during these periods; it also demonstrates that the AAE is a function of wavelength. During these periods the AAE was larger at shorter wavelengths, as expected for organic carbon as discussed below. There appear to be two different source types in Fig. 2. $80 \%$ of the data has an AAE around 1 consistent with urban pollution (diesel exhaust) and $20 \%$ has an AAE from 1.5 to 3 consistent with organic carbonaceous particles. The fact that some of the data have an AAE less than 1 is interesting. This could be a result of measurement uncertainties or that the imaginary part of the index of refraction increases slightly with wavelength for some of the particles. There is no physical reason why the index of refraction for LAC should be constant with wavelength and, in fact, the index of refraction does increase in the infrared (see the data sources cited in Bond and Bergstrom, 2006).

\section{Absorption by individual components}

The wavelength dependence of absorption depends upon the spectra of component aerosols and also their size, shape or mixing state. Here, we discuss spectra of different absorbing aerosol species and how they contribute to aerosol measured in field campaigns. The current climate models need to attribute the absorption properties to individual aerosol

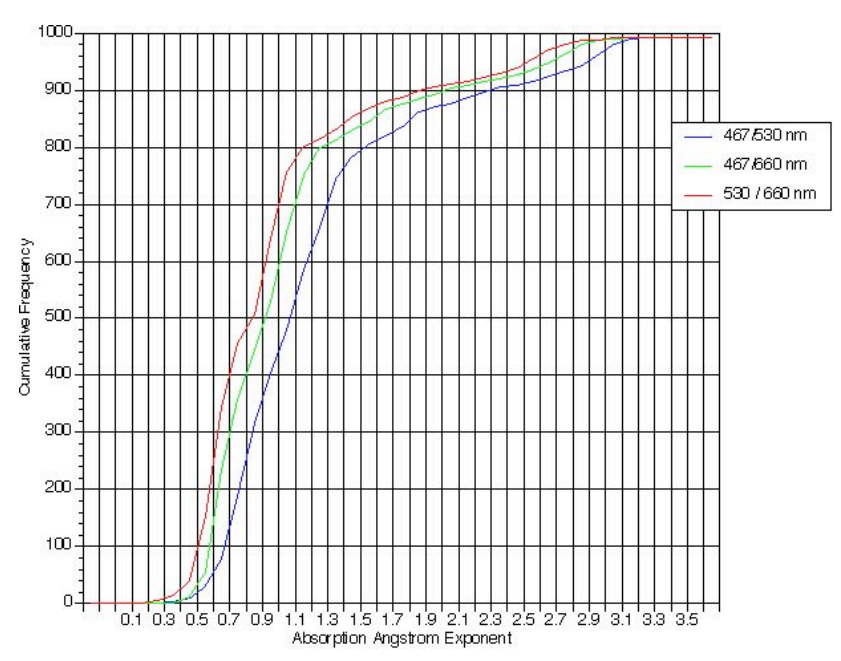

Fig. 2. The aerosol Absorption Angstrom Coefficient for offshore flow conditions during the GoMACCS field campaign derived from PSAP measurements onboard the NOAA RV Ronald H. Brown.

species; however, the measured values from field programs constrain the models predictions.

\subsection{Carbonaceous aerosols}

Carbonaceous particles that absorb solar radiation can be divided into highly absorbing carbon particles (termed either black carbon - BC or light absorbing carbon - LAC, Bond and Bergstrom (2006)) and weakly absorbing organic carbon particles (so-called brown carbon). As mentioned above, LAC particles typically have an AAE of 1.

Andreae and Gelenscer (2006) discussed the importance of distinguishing between black carbon and brown carbon. They noted that the less absorbing carbonaceous particles tend to have a larger AAE than LAC (e.g., Bond, 2001; Kirchstetter et al., 2004; Schnaiter et al., 2003). Kirchstetter et al. (2004) present a table of measurements of the spectral absorption by carbonaceous atmospheric aerosols. The AAE values range from 1 to 3 for ranges mostly between $300 \mathrm{~nm}$ to $1000 \mathrm{~nm}$. In Table 2 we have listed several recent 
measurements of organic carbonaceous aerosols made since the Kirchstetter et al. (2004) tabulation.

In Fig. 1 both the TARFOX and ICARTT absorption was measured off the North Atlantic coast of the United States for offshore flow conditions dominated by urban pollution (presumably containing diesel emissions). Diesel particle emissions are routinely measured as having an AAE about 1 (Schnaiter et al., 2003).

Additional shipboard and aircraft data with filter-based measurements. corroborate the value of AAE equal to 1 for ICARTT. Measurements from the NOAA ship Ronald H. Brown for the same day as the case study (21 July 2004) (Sierau et al., 2006) give an AAE of 1.0, in good agreement with the results in Fig. 1. Virkkula et al. (2005) measured the AAE in the New England Air Quality Study experiment in 2002 (in the same location but two years earlier than the ICARTT experiment) as 1.18. Clarke et al. (2007) found that for the INTEX A field program (the NASA component of ICARTT), aerosol with an urban pollution origin had an AAE around 1, and aerosol from biomass burning plume had an AAE of around 2.1.

The variability in the AAE shown in Fig. 2 is due in part to mixtures of emissions from various sources but also variability from an individual source. Roden et al. (2006) measured the AAE of emissions of carbonaceous aerosol from cooking stoves, capturing emission events in real time. Many events show AAE of 1.0 and a single scattering albedo of 0.2 (indicative of LAC). Another cluster of events extends to higher single scattering albedo values and higher AAE values (0.8 single scattering albedo and an AAE of 5) indicative of brown carbon. Thus the cooking stove source contains both types of carbonaceous aerosols.

Kirchstetter et al. (2004) presented measurements of the absorption of solar radiation by aerosols collected on filters. They found that absorption due to motor vehicle exhaust had an AAE of about 1while biomass burning plumes had an AAE of approximately 2 (similar to the results of Clarke, 2007). Schnaiter et al. (2005) deduced AAE of 1.3 for Diesel soot and 2.2 for spark generated soot and Schnaiter et al. (2006) measured AAE's of 2.2 to 3.5 for increasing organic carbon content in combustion soots.

To explain why the AAE is a function of wavelength it is helpful to use the band-gap theory of absorption. The bandgap theory was originally proposed by Tauc (1966) and was applied to the absorption of semiconducting amorphous carbon by Robertson and O'Reilly (1987). (The band-gap is the energy necessary to cause an electronic transition for a particular material.) Bond (2001), Kirchstetter et al. (2004) and Schnaiter et al. (2003) have used the theory to explain the absorption by organic carbon particles. This theory provides an analytical expression for the AAE and shows that in general the AAE is not a constant with respect to wavelength (except for black carbon).

Sun et al. (2007) show that the AAE for a particular material is equal to $\left(E+E_{g}\right) /\left(E-E_{g}\right)$ where $E$ is the energy of the photon $(E=h c / \lambda)$ and $E_{g}$ is the band-gap. For LAC (black carbon), $E_{g}$ is zero and AAE is one, in agreement with some of the observed data. Sun et al. (2007) suggest two types of materials to represent absorption by organic carbon particles: a humic-like material and a combustion-like material. The absorption coefficients for the material proposed by Sun et al. (2007) have a larger AAE than LAC particles but can be approximated with an AAE of 6 for the humic substances and an AAE of 4.3 for the combustion substances. Mixtures of these materials and LAC will have AAE greater than 1 but less than 4-6, which could explain some observations. These coefficients also explain why the sources that Roden et al. (2006) measured can have such a wide range of AAE since the fluctuation between LAC and other organic material is highly variable in solid-fuel emissions.

\subsection{Dust aerosols - PRIDE}

There is a large amount of information on the absorption properties of mineral dust that we will not summarize here. Sokolik and Toon (1999) and Lafon et al. (2005) showed the wavelength dependence of the absorption for various materials that make up desert dust (primarily hematite and certain clays). While many types of mineral dust have a very complicated wavelength structure at infrared wavelengths, absorption at visible wavelengths is often smooth and decreases at greater wavelengths.

Collaud Coen et al. (2004) measured the scattering and absorption wavelength dependence during Saharan dust events at the Jungefraujoch, showing that the AAE of the Saharan dust particles increased from above 1 to a range between 1 and 2. Fialho et al. (2005) also used the magnitude of the AAE to differentiate between Saharan dust and LAC particles. They estimated the dust particles had an AAE of 2.9 similar to our results for the PRIDE case in Fig. 1.

\subsection{Mixed urban pollution and desert dust aerosols - ACE Asia}

As discussed in Bergstrom et al. (2004), the ACE Asia program sampled aerosol that had both urban pollution and desert dust components. The AAE of 2.2 from the data in Fig. 1 is consistent with elevated AAE due to either dust or carbonaceous material. However, it is impossible to extract from the AAE alone the relative amounts of each component.

\section{Single scattering albedo}

The spectral single scattering albedo, or the ratio of scattering to extinction (absorption plus scattering), is commonly presented in the literature since it can determine the sign of the aerosol radiative effects. However, very often the aerosol that contributes the absorption is not the same as the aerosol that dominates the scattering. For example, pure LAC particles typically have a single scattering albedo of 0.2 . 
Table 2. Measurements of AAE for carbonaceous particles made since Kirchstetter et al. (2004).

\begin{tabular}{lllll}
\hline Reference & Comments & Spectral & AAE & $\begin{array}{l}\text { SSA } \\
\text { Range }\end{array}$ \\
& & & - \\
& biomass & $300-1000$ & 2.0 & - \\
\hline Kirchstetter et al., 2004 & auto exhaust & $300-1000$ & 1.0 & - \\
& diesel soot & $450-700$ & 1.1 & 0.2 \\
Schnaiter et al., 2003 & spark discharge soot & $450-700$ & 2.1 & $0.25-0.3$ \\
& biomass burning & $450-700$ & $1.5-1.9$ & 0.74 \\
Schnaiter et al., 2005 & soot OC $<20 \%$ & $200-1000$ & 1.0 & 0.3 \\
Schnaiter et al., 2006 & soot OC 50\% & $200-1000$ & $2.2-3.5$ & 0.7 \\
& NE US & $467-660$ & 1.18 & - \\
Virkkula et al., 2005 & Biomass smoke & $467-660$ & 2.1 & $0.8-1.0$ \\
Clarke et al., 2007 & Urban pollution & $467-660$ & 1.0 & $0.8-1.0$ \\
\multirow{3}{*}{ GoMACCS data compilation } & Texas Gulf coast & $467-660$ & $1.0-3.0$ & $0.8-1.0$ \\
Roden et al., 2006 & cooking stoves & $467-660$ & $1-5$ & $0.2-0.8$ \\
\hline
\end{tabular}

Absorption in urban pollution is thought to be dominated by LAC, but because the scattering is due to sulfates or organic aerosol, the total aerosol may have a single scattering albedo at $550 \mathrm{~nm}$ of between 0.8 to 0.95 depending on the LAC content. Also, the wavelength dependence of the scattering is a strong function of the size of the particles so the single scattering albedo's wavelength dependence is a function of both the composition and size of the aerosols.

The spectral single scattering albedo variation with wavelength is different for dusts (it tends to increase) than for urban pollution (it tends to decrease) (Bergstrom et al., 2002; Dubovik et al., 2002). Collaud Coen et al. (2004) and Meloni et al. (2006) found that they could differentiate between carbonaceous aerosols and Saharan dust because the dust had a single scattering albedo that increased with wavelength while for urban pollution and biomass burning aerosol the single scattering albedo decreased with wavelength.

The single scattering albedo spectra for the above cases are shown in Fig. 3. For large particles (like dust) the scattering is fairly constant with wavelength so the single scattering albedo matches the decrease in absorption with wavelength. For smaller particles (like urban pollution) the scattering often decreases faster than absorption of the carbonaceous particles so that the single scattering albedo decreases with wavelength.

\section{Conclusions}

For the case studies from 5 field programs shown in Fig. 1 the decrease of the aerosol absorption with wavelength can be fit with a power-law expression (AAE) yielding AAE that range from 1.0 to 2.3. In general the AAE values for carbonaceous particles are greater than 1 (near one for urban pollution; nearer two for biomass smoke). For dusts the AAE values are large (around 3) and perhaps only approximately
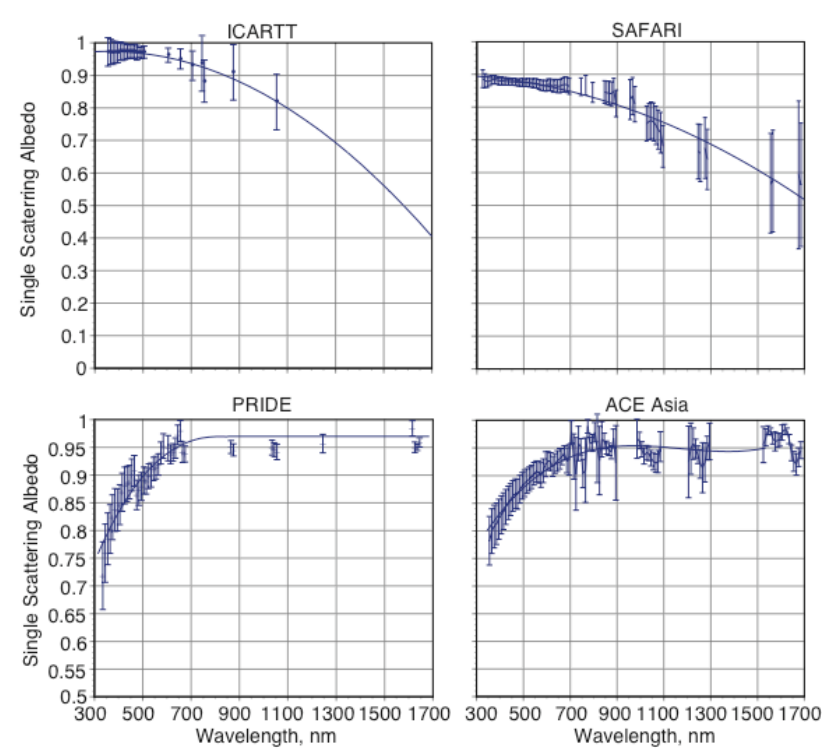

Fig. 3. The single scattering albedo for the cases presented in Fig. 1.

fit by a power law. The AAE may be a useful approximation for climate models but is probably less applicable for calculations of the radiance in specific wavelength regions like the UV where the AAE may be different than in the visible. Use of the AAE to represent wavelength dependence can account for spectral differences due to chemical composition to a greater extent than has been previously accomplished. However, there is no reason why the AAE should be constant with wavelength, and it should be used with care, particularly when relating measurements of visible and ultraviolet absorption.

Although the AAE can be very high (4-6) for individual organic carbonaceous compounds, in the atmosphere these compounds are usually mixed with strongly absorbing 
particles (LAC). Therefore the average AAE usually lies between 1 (for LAC) and 4-6.

As the UV spectral region is important for photochemical reactions and the TOMS/OMI type of remote sensing, it is important to account for the difference between the UV and visible absorption. For aerosol with an AAE of 3 the absorption coefficient at a wavelength of $275 \mathrm{~nm}$ will be 8 times the value at $550 \mathrm{~nm}$. There clearly is a need to measure the spectral variation of aerosol absorption in future field programs.

Acknowledgements. The authors gratefully acknowledges support provided by NASA's Earth Observing System Interdisciplinary Science (EOS-IDS) Program and by NASA's Radiation Sciences Program.

Edited by: T. Kirchstetter

\section{References}

Andreae, A. and Gelecser, A.: Black carbon or brown carbon? The nature of light-absorbing carbonaceous aerosols, Atmos. Chem. Phys., 6, 3131-3148, 2006,

http://www.atmos-chem-phys.net/6/3131/2006/.

Bates, T. S., Anderson, T. L., Baynard, T., et al.: Aerosol direct radiative effects over the northwest Atlantic, northwest Pacific, and North Indian Oceans: estimates based on in-situ chemical and optical measurements and chemical transport modeling, Atmos. Chem. Phys., 6, 1657-1732, 2006,

http://www.atmos-chem-phys.net/6/1657/2006/.

Bergstrom, R. W., Pilewskie, P., Pommier, J., Rabbette, M., Russell, P. B., Schmid, B., Redemann, J., Higurashi, A., Nakajima, T., and Quinn, P. K.: Spectral absorption of solar radiation by aerosols during ACE-Asia, J. Geophys. Res., 109, D19S15, doi:10.1029/2003JD004467, 2004.

Bergstrom, R. W., Pilewskie, P., Schmid, B., and Russell, P. B.: Comparison of Measured and Predicted Aerosol Radiative Effects during SAFARI 2000, J. Geophys. Res., 108, D138474, doi:1029/2002JD002435, 2003.

Bergstrom, R. W., Russell, P. B., and Hignett, P. B.: The Wavelength Dependence of Black Carbon Particles: Predictions and Results from the TARFOX experiment and Implications for the Aerosol Single Scattering Albedo, J. Atmos. Sci., 59, 567-577, 2002.

Bergstrom, R. W.: Extinction and Absorption Coefficients of the Atmospheric Aerosol as a Function of Particle Size, Contr. Atmos. Phys., 46, 223-234, 1973.

Bohren, C. F. and Huffman, D. R.: Absorption and scattering of light by small particles, John Wiley and Sons, New York, 530 pp., 1983.

Bond, T. C. and Bergstrom, R. W.: Light absorption by carbonaceous particles: An investigative review, Aerosol Sci. Technol., 40, 27-67, 2006.

Bond, T. C., Habib, G., and Bergstrom, R. W.: Limitations in the Enhancement of Visible Light Absorption due to Mixing State, J. Geophys. Res., 111, D20211, doi:10.1029/2006JD007315, 2006.

Bond, T. C. and Sun, H.: Can Reducing Black Carbon Emissions Counteract Global Warming?, Environ. Sci. Technol., 39, 59215926, 2005.
Bond, T. C.: Spectral Dependence of Visible Light Absorption by Carbonaceous Particles Emitted from Coal Combustion, Geophys. Res. Lett., 28(21), 4075-4078, 2001.

Clarke, A., McNaughton, C., Kapustin, V., Shinozuka, Y., Howell, S., Dibb, J., Zhou, J., Anderson, B., Brekhovskikh, V., Turner, H., and Pinkerton, M.: Biomass Burning and Pollution Aerosol over North America: Organic Components and their influence on Spectral Optical Properties and Humidification Response, J. Geophys. Res., 112, D12S18, doi:10.1029/2006JD007777, 2007.

Collaud Coen, M., Weingartner, E., Schaub, D., Hueglin, C., Corrigan, C., Henning, S., Schikowski, M., and Baltensperger, U.: Saharan dust events at the Jungfraujoch: Detection by wavelength dependence of the single scattering albedo and first climatology analysis, Atmos. Chem. Phys., 4, 2465-2480, 2004, http://www.atmos-chem-phys.net/4/2465/2004/.

Dubovik, O., Holben, B. N., Eck, T. F., Smirnov, A., Kaufman, Y. J., King, M. D., Tanre, D., and Slutsker, I.: Climatology of atmospheric aerosol absorption and optical properties in key locations, J. Atmos. Sci., 59, 590-608, 2002.

Fialho, P., Hansen, A. D. A., and Honrath, R. E.: Absorption coefficients by aerosols in remote areas: A new approach to decouple dust and black carbon absorption coefficients using sevenwavelength Aethalometer data, J. Aerosol Sci., 36(2), 267-282, 2005.

Hansen, A. D. A., Rosen, H., and Novakov, T.: The aethalometer - an instrument for the real-time measurement of optical absorption by aerosol particles, Sci. Total Env., 36, 191-196, 1984.

Climate Change 2007: The Physical Science Basis, Contribution of Working Group 1 to the Fourth Assessment Report of the IPCC, ISBN 9780521 88009-1 Hardback, 9780521 70596-7 Paperback, Cambridge University Press, 2007.

Kirchstetter, T. W. , Novakov, T., and Hobbs, P.: Evidence that the spectral dependence of light absorption by aerosols is affected by organic carbon, J. Geophys. Res., 109, D21208, doi:10.1029/2004JD004999, 2004.

Lafon, S., Sokolik, I. N., Rajot, J. L., Caquineau, S., and Gaudichet, A.: Characterization of iron oxides in mineral dust aerosols: Implications for light absorption, J. Geophys. Res., 111, D21207, doi:10.1029/2005JD007016, 2006.

Meloni, D., di Sarra, A., Pace, G., and Monteleone, F.: Aerosol optical properties at Lampedusa (Central Mediterranean). 2. Determination of single scattering albedo at two wavelengths for different aerosol types, Atmos. Chem. Phys., 6, 715-727, 2006, http://www.atmos-chem-phys.net/6/715/2006/.

Pilewskie, P., Pommier, J., Bergstrom, R. W., et al.: Solar spectral radiative forcing during the Southern African Regional Science Initiative, J. Geophys. Res., 108(D13), 8486, doi:10.1029/2002JD002411, 2003.

Redemann, J., Pilewskie, P., Russell, P. B., et al.: Airborne measurements of spectral direct aerosol radiative forcing in INTEX/ITCT, J. Geophys. Res., 111, D14210, doi:10.1029/2005JD006812, 2006.

Reid, J. S., Kinney, J. E., Westphal, D. L., et al.: Analysis of measurements of Saharan dust by airborne and groundbased remote sensing methods during the Puerto Rico Dust Experiment (PRIDE), J. Geophys. Res., 108(D19) 8586, doi:10.1029/2002JD002493, 2003.

Reid, J. S., Eck, T. F., Christopher, S. A., Hobbs, P. V., and Hol- 
ben, B.: Use of the Angstrom exponent to estimate the variability of optical and physical properties of ageing smoke particle in Brazil, J. Geophys. Res., 104(D22), 27 473-27 490, 1999.

Robertson, J. and O'Reilly, E. P.: Electronic and atomic structure of amorphous carbon, Phys. Rev. B, 35(6), 2946-2957, 1987.

Roden, C. A., Bond, T. C., Conway, S., Benhamin, A., and Pinel, O.: Emission factors and real-time optical properties of particles emitted from traditional wood burning cookstoves, Environ. Sci. Technol., 40, 6750-6757, 2006.

Russell, P. B., Livingston, J. M., Hignett, P., Kinne, S., Wong, J., and Hobbs, P. V.: Aerosol induced radiative flux changes off the United States Mid-Atlantic coast: Comparison of values calculated from sunphotometer and in situ data with those measured by airborne pyranometer, J. Geophys. Res., 104, 2289-2307, 1999.

Schnaiter, M., Horvath, H., Mohler, O., Naumann, K. H., Saathoff, H., and Schock, O. W.: UV-VIS-NIR spectral optical properties of soot and soot-containing aerosols, J. Aerosol Sci., 34, 14211444, 2003.

Schnaiter, M., Schmid, O., Petzold, A., Fritzsche, L., Klein, K. F., Andreae, M. O., Helas, G., Thielmann, A., Gimmler, M., Mohler, O. M., Linke, C., and Schurath, U.: Measurement of wavelength resolved light absorption by aerosols utilizing a UV-VIS extinction cell, Aerosol Sci. Technol., 39, 249-260, 2005.

Schnaiter, M., M. Gimmler, I. Llamas, C. Linke, C. J"ager, and H. Mutschke: Strong spectral dependence of light absorption by organic carbon particles formed by propane combustion, Atmos. Chem. Phys., 6, 2981-2990, 2006,

http://www.atmos-chem-phys.net/6/2981/2006/.
Sierau, B., Covert, D. S., Coffman, D. J., Quinn, P. K., and Bates, T. S.: Aerosol optical properties during the 2004 New England Air Quality Study-Intercontinental Transport and Chemical Transformation: Gulf of Maine surface measurements Regional and case studies, J. Geophys. Res., 111, D23S37, doi:10.1029/2006JD007568, 2006.

Sokolik, I. and Toon, O. B.: Incorporation of mineralogical composition into models of the radiative properties of mineral aerosol from UV to IR wavelengths, J. Geophys. Res., 104, 9423-9444, 4501-4512, 1999.

Sun, H., Biedermann, L., and Bond, T. C.: The color of brown carbon: A model for ultraviolet and visible light absorption by organic carbon aerosol, Geophys. Res. Lett., 34, L17813, doi:10.1029/2007GL029797, 2007.

Tauc, J., Grigorovici, R., and Vancu, A.: Optical properties and electronic structure of amorphous germanium, Phys. Stat. Sol., 15, 627-637, 1966.

Torres, O., Bhartia, P. K., Sinyuk, A., Welton, E. J., and Holben, B.: Total Ozone Mapping Spectrometer measurements of aerosol absorption from space: Comparison to SAFARI 2000 ground-based observations, J. Geophys. Res., 110, D10S18, doi:10.1029/2004JD004611, 2005.

Virkkula, A., Ahlquist, N. C., Covert, D. S., Arnott, W. P., Sheridan, P. J., Quinn, P. K., and Coffman, D. J.: Modification, calibration and a field test of an instrument for measuring light absorption by particles, Aerosol Sci. Technol., 39(1), 68-83, 2005. 